\title{
Cochlear Implant Failure due to Cochlear Nerve Deficiency in a Child with Normal Internal Auditory Canal
}

\author{
So-Hyang Kim, Sung-Wook Jeong and Lee-Suk Kim \\ Department of Otolaryngology-Head and Neck Surgery, Dong-A University College of Medicine, Busan, Korea
}

\section{정상 내이도를 가진 난청 아동에서 와우신경부전으로 인한 인공와우이식 실패 1 예}

김소향 · 정성욱 · 김리석

동아대학교 의과대학 이비인후과학교실

\author{
Received September 10, 2010 \\ Revised October 19, 2010 \\ Accepted October 19, 2010 \\ Address for correspondence \\ Sung-Wook Jeong, MD, PhD \\ Department of Otolaryngology-Head \\ and Neck Surgery, \\ Dong-A University College of \\ Medicine, 3-1 Dongdaeshin-dong, \\ Seo-gu, Busan 602-715, Korea \\ Tel $+82-51-240-5428$ \\ Fax $+82-51-253-0712$ \\ E-mailsu0305@lycos.co.kr
}

The cochlear nerve, which propagates electrical signals to the auditory cortex, must function well for successful cochlear implantation. A narrow internal auditory canal (IAC) increases the risk of hypoplasia or aplasia of cochlear nerve, which may result in the failure of cochlear implantation. Therefore, a functioning cochlear nerve must be verified before deciding to do cochlear implantation by means of behavioral audiometry, electrophysiologic tests, or imaging studies in cases with narrow IAC. On the other hand, a candidate with a normal IAC can be overlooked in investigating the presence of functioning cochlear nerve. Because normal IAC does not always guarantee the presence of normal cochlear nerve, the functioning cochlear nerve should be proved prior to cochlear implantation in those cases. We report on a child, who had normal IAC and cochlea but failed auditory stimulation after cochlear implantation, and who was diagnosed as having cochlear nerve deficiency through retrospective review. Korean J Otorhinolaryngol-Head Neck Surg 2010;53:729-32

Key Words Cochlear implantation · Cochlear nerve · Internal auditory canal.

\section{서 론}

성공적인 인공와우이식을 위해서는 소리자극에 의해 인 공와우에서 발생한 전기적 신호를 대뇌청각피질까지 전달할 와우신경(cochlear nerve)의 존재가 필수적이며, 기능하는 와우신경의 존재는 수술 전 다양한 청력검사와 영상학적 검 사를 통해 확인할 수 있다. ${ }^{1,2)}$ 특히 측두골 전산화 단층촬영 (temporal bone computed tomography, TBCT)에서 내 이도 협착이 있는 경우에는 와우신경의 저형성이나 무형성 의 가능성이 높기 때문에,,$^{3-5)}$ 내이도 자기공명영상(internal auditory canal magnetic resonance image, IAC MRI) 을 통해 와우신경을 확인하고 순음청력검사나 전기생리학 적 검사를 통해 기능하는 와우신경의 존재를 확인해야 한
다. IAC MRI에서 와우신경이 관찰되지 않고 청력검사에서 소리 자극에 대한 주관적 혹은 객관적 반응이 확인되지 않 는 경우에는 와우갑각 자극검사(promontory stimulation test, PST)나 전기자극 청성뇌간반응(electrical auditory brainstem response, EABR)을 시행하여 전기자극에 대 한 주관적 혹은 객관적 반응을 확인하거나 기능적 뇌 영상 (functional brain image)을 통해 기능하는 와우신경의 존재를 확인할 수 있다. ${ }^{1,2}$ 반면 내이도 협착이 없는 경우에 는 와우신경 무형성이나 저형성의 가능성이 적어 와우신경 에 대한 평가가 간과될 수 있다. 저자들은 수술 전 영상검사 에서 와우와 내이도의 구조적 이상이 없던 소아 난청 환자 에서 인공와우이식 후 청각 자극에 실패하여 후향적 조사 를 통해 와우신경부전(cochlear nerve deficiency)을 진단 
한 예를 경험하였기에 이를 보고하고자 한다.

\section{증 례}

타 병원에서 우측 인공와우이식을 시행하고 2 년 3 개월이 경과한 3 세 7 개월의 여아가 인공와우를 통해 소리를 들을 수 없어 본원에 내원하였다. 과거 의무기록에 따르면 아동은 생후 13 개월에 난청과 언어발달 지연을 주소로 타 병원을 방문하였다. 당시 양측 고막은 정상이었고 유발 이음향방사 와 등골 반사는 나타나지 않았다. 청성뇌간반응검사에서 양 측 귀 모두 최고 강도의 음 자극에도 반응을 보이지 않았 고, 청성지속반응검사에서는 우측 귀는 최고 강도의 음자 극에 반응이 없었고 좌측 귀는 $100 \mathrm{dBHL}$ 의 역치를 보였 다. $\mathrm{TBCT}$ 와 IAC MRI에서 양측 수평반고리관에 국한된 기 형은 있었으나 양측 와우와 내이도의 구조적 이상은 없었으 며, 안면신경과 상-하 전정신경은 확인되었으나 와우신경은 정확히 관찰되지 않았다(Fig. 1). 양측 심도 감각신경성난청 으로 양측 보청기를 착용하고 청각 재활을 시작하였으나 환 경음 및 말소리에 대한 신뢰성 있는 반응을 관찰할 수 없었 고 보청기의 이득이 부족하여 생후 16 개월에 우측 인공와 우이식[CI24RE(CA), Cochlear Ltd, Australia]을 시행하
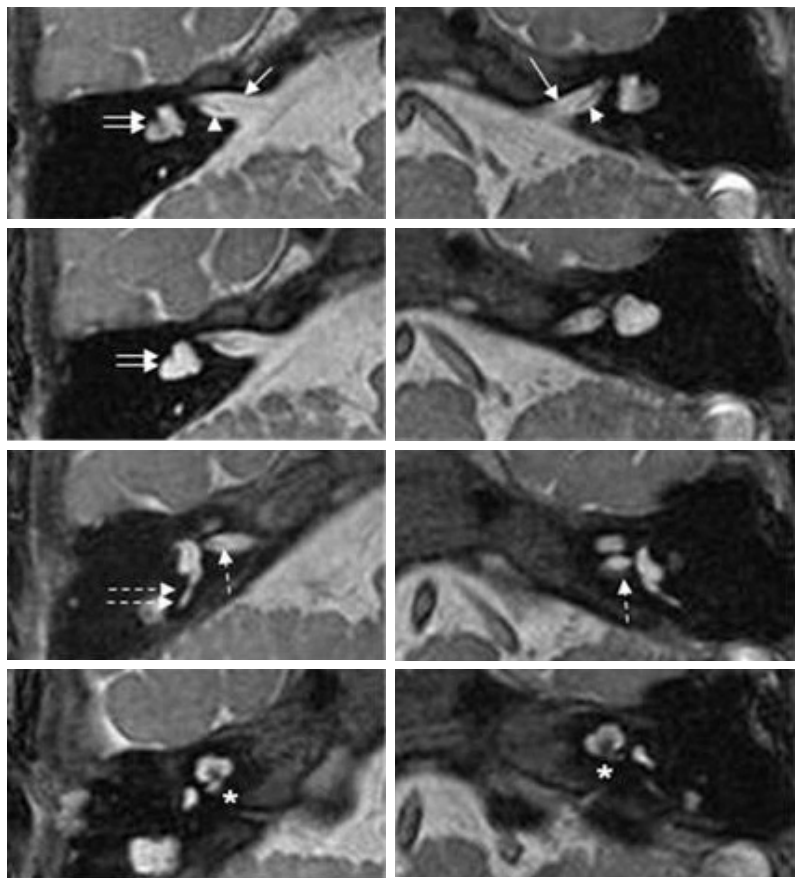

Fig. 1. Preoperative magnetic resonance image of internal auditory canal. Bilateral cochleas and internal auditory canals (IAC) show normal appearance. There are facial nerves (arrow), superior vestibular nerves (arrow head) and inferior vestibular nerves (dashed arrow) in bilateral IACs, but cochlear nerves are not identified (double arrows, vestibule and lateral semicircular canal; double dashed arrows, posterior semicircular canal; asterisk, modiolus of cochlea).
였다. 수술 당시 22 개의 전극을 이상 없이 와우 내로 삽입하 였고, 모든 전극의 저항은 정상 범위였다. 신경반응 원격측 정검사(neural response telemetry, NRT)를 시행한 10개 의 전극 중 4 개의 전극에서 전기자극 복합활동전위의 파형 이 관찰되었다. 그러나 술 후 지속적인 청각재활 훈련에도 불구하고 아동은 인공와우를 통해 환경음과 말소리를 감지 하지 못하였다.

이후 본원에 내원하여 시행한 순음청력검사에서 우측 귀 는 전주파수에서 최대 강도의 자극음에도 반응이 없었고, 좌측 귀의 기도청력역치는 평균 $98 \mathrm{dBHL}$ 이었다(Fig. 2). 인공와우 착용 후 시행한 순음청력검사에서 최대 강도의 음 자극에도 반응이 없었고, NRT와 EABR에서도 모든 전극 에서 최대 강도의 전기자극에도 반응을 보이지 않았다. 인공 와우를 착용하고 시행한 언어 평가에서 Ling 6 sound 검사 의 모든 소리를 감지하지 못하였고, 환경음과 말소리에 대 한 반응을 관찰할 수 없었다. 어음처리기에는 이상이 없었으 며, 새로운 어음처리기로 교체한 후에도 소리를 감지하지 못 하였다. 내부 기기의 이상 여부를 확인하기 위해 TBCT와 integrity test를 시행하였으며 전극의 위치나 기기 작동에는 이상이 없음을 확인하였다(Fig. 3). 내부 기기와 어음처리 기의 이상이 없음에도 불구하고, 전기자극에 대한 객관적 신경반응과 주관적 행동반응이 없으며 MRI에서 와우신경 이 확인되지 않았기 때문에 우측 와우신경부전을 이식 실패 의 원인으로 진단하였다.

아동은 생후 4년 4개월에 좌측 인공와우이식[CI24RE (CA), Cochlear Ltd, Australia]을 받았다(Fig. 4). 술 후 12 개월에 시행한 순음청력검사에서 인공와우 착용 시 청력

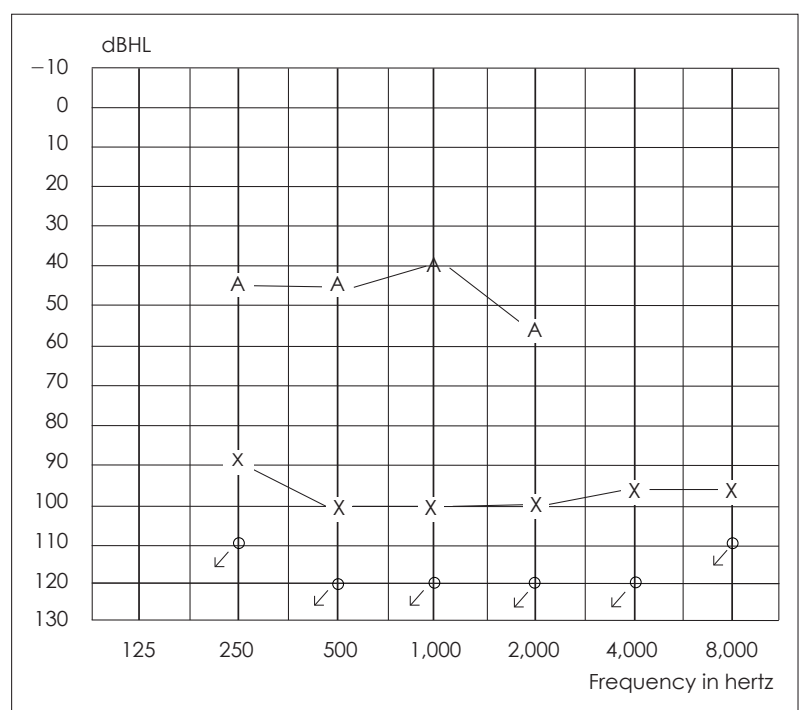

Fig. 2. Pure tone audiogram obtained 27 months after right cochlear implantation. Capital A indicates left ear hearing responses with hearing aid. 


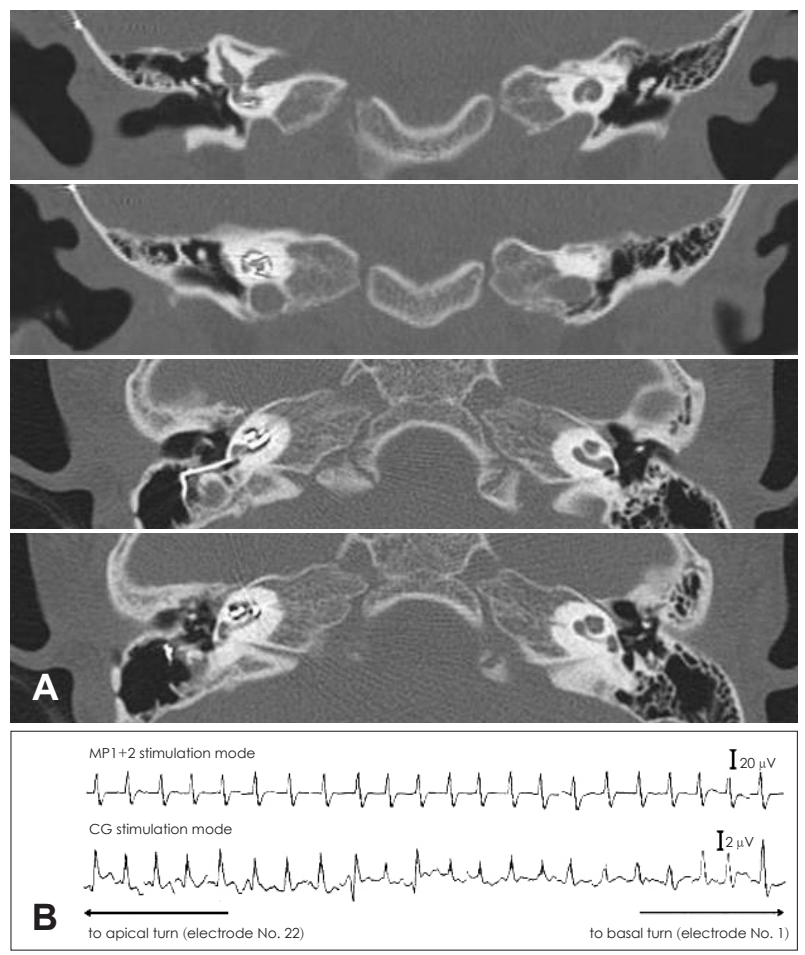

Fig. 3. The result of temporal bone computed tomography $(A)$ and integrity test $(B)$ taken after right cochlear implantation. Electrode array is positioned properly in right cochlea (A). In integrity test with common ground (CG) and monopolar 1+2 (MP 1+2) modes of stimulation, electrical signals equivalent to the biphasic stimulation pulse are recorded, which show that internal device works normally (B).

역치는 $35 \mathrm{dBHL}$ 이었고(Fig. 5), 단음절단어검사에서 음소 점수는 $44 \%$, 단어 점수는 $16 \%$ 였으며, Categories of $\mathrm{Au}-$ ditory Performance 점수는 4 로 지속적인 언어발달을 보 이고 있는 상태이다.

\section{고 찰}

$\mathrm{TBCT}$ 에서 내이도의 너비가 $2 \mathrm{~mm}$ 이하인 내이도 협착 이 있는 경우에는 와우신경의 저형성 혹은 무형성의 가능 성이 있으며, 이는 인공와우이식 실패의 원인이 될 수 있다. Shelton 등흔 인공와우이식 후 소리를 감지하지 못한 환 자 3명의 $\mathrm{TBCT}$ 에서 내이도 협착이 있었다고 보고하면서 내이도 협착을 인공와우이식 수술의 금기로 제안하였다. Gray 등 ${ }^{4}$ 도 인공와우이식 후 소리를 감지하지 못한 환자에 서 이식 실패의 원인을 찾기 위해 $\mathrm{TBCT}$ 를 재 촬영한 결과 내이도 협착을 발견하여 인공와우를 제거하고, $\mathrm{MRI}$ 촬영 을 통해 와우신경부전을 진단하였다. Maxwell 등흐은 영상 검사에서 양측 내이도 협착, 좌측 와우신경 무형성, 그리고 우측 와우신경 저형성의 소견을 보인 난청 아동에서 우측

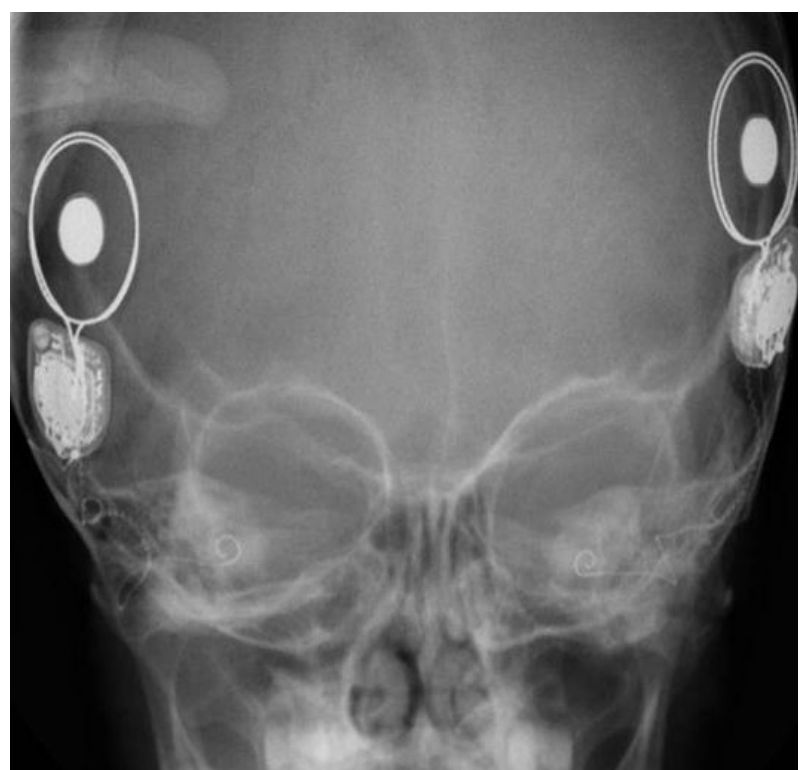

Fig. 4. Postoperative transorbital X-ray shows well-positioned electrode arrays in bilateral cochleas.

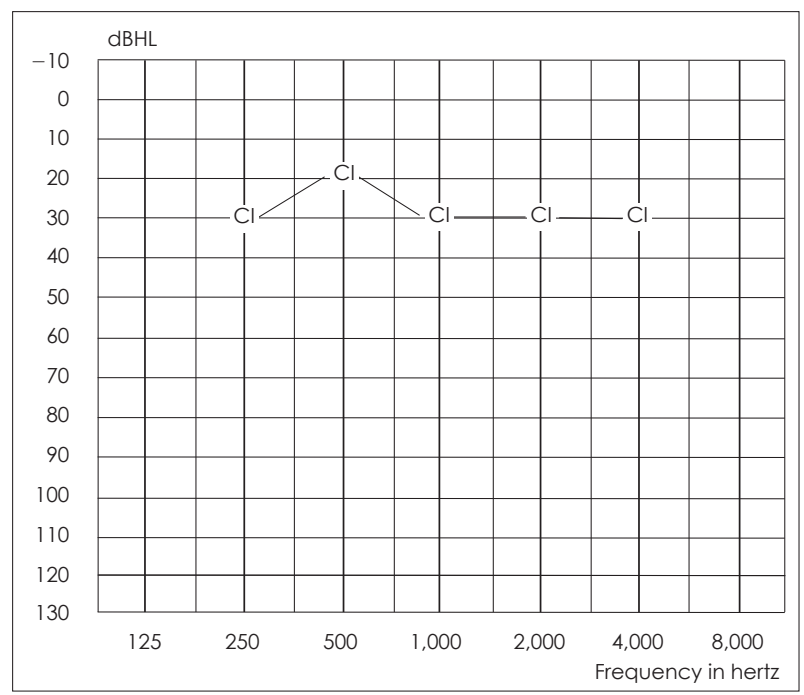

Fig. 5. Pure tone audiogram obtained 24 months after left cochlear implantation. Hearing thresholds with left cochlear implant are below $30 \mathrm{dBHL}$ across all frequencies.

인공와우이식을 시행하였으나, 이식 후 소리를 감지하지 못 하고 안면신경 자극이 발생하여 인공와우를 제거한 예를 보고하였다. 이와 같이 내이도 협착이 있는 경우에는 와우 신경의 부전으로 인해 인공와우이식 후 소리를 감지하지 못 하거나, ${ }^{3-5)}$ 청각적 수행력이 매우 부진할 수 있으므로 술 전 와우신경에 대한 면밀한 평가가 필요하다. ${ }^{6.7)}$

반면 내이도 협착이 없는 경우에는 와우신경부전의 가능 성은 적다. 하지만 정상 내이도가 정상 와우신경의 존재를 항상 보장하는 것은 아니기 때문에 내이도가 정상이라도 와 우신경에 대한 평가는 필요하다. Nelson과 Hinojosa ${ }^{8}$ 는 일 
측성 난청이 있었던 환자의 사후 측두골 병리 소견에서 와 우의 구조는 정상이고 내이도 협착은 없었음에도 불구하고 나선신경절 세포와 와우신경이 존재하지 않았다고 보고하 였다. Casselman 등 ${ }^{9}$ 은 영상검사에서 내이도는 정상이나 와우신경의 저형성증 혹은 무형성증이 있었던 3 명의 선천성 난청 아동을 보고하였다. Adunka 등 ${ }^{10)}$ 도 MRI에서 와우신 경부전의 소견을 보인 19 명의 환자(와우신경 무형성 16 명, 와 우신경 저형성 3 명) 중 11 명은 직경 $3 \mathrm{~mm}$ 이상의 정상적인 내이도를 가지고 있었다고 보고한 바 있다.

기능하는 와우신경의 존재 여부는 행동반응 청력검사, 전 기생리학적 검사, 그리고 영상검사를 통해 확인할 수 있다. 행동반응 청력검사에서 소리자극에 대한 반복적이고 신뢰 할 만한 행동 반응을 보이거나 청성뇌간반응과 같은 전기생 리학적 검사에서 소리자극에 의해 뇌파가 기록되는 경우에 는 기능하는 와우신경이 존재한다고 볼 수 있다. 와우신경의 존재는 $\mathrm{MRI}$ 를 통해서도 확인할 수 있으며, 정확한 평가를 위해서는 $0.7 \mathrm{~mm}$ 이하의 절편 두께로 thin gradient echo image의 MRI 영상을 얻는 것이 좋다. ${ }^{11)}$ 또한 축상 영상 (axial image)과 함께 와우신경의 주행에 수직으로 준시상 영상(parasagittal image)을 얻어 두가지 차원의 영상을 비 교하면 와우신경의 상태를 보다 정확하게 평가할 수 있다. ${ }^{11)}$

만일 행동반응 청력검사와 전기생리학적 검사에서 청각 반응이 확인되지 않고 MRI에서도 와우신경이 확인되지 않 는 경우에는, 전기자극을 이용한 검사를 통해 와우신경의 존재를 확인할 수 있다. 즉 PST에서 전기자극에 대한 주관 적 반응을 보이거나 $\mathrm{EABR}$ 에서 뇌파가 기록되는 경우에는 기능하는 와우신경이 존재하는 것으로 볼 수 있다. 그 외에 기능적 자기공명영상(functional MRI), 양전자 방사 단층 촬영(positron emission tomography)과 같은 기능적 뇌 영상은 소리 자극에 대해 와우와 대뇌청각피질이 기능적으로 연결되어 있는지를 보여주는 영상검사 방법으로, 기능하는 와우신경의 존재를 증명해 주는 유용한 방법이 될 수 있다. ${ }^{12)}$

난청의 조기 발견으로 2 세 이전의 인공와우이식이 널리 행해지고 있고, 최근에는 신생아 청각선별검사의 도입으로 1 세 경의 수술도 증가하는 추세이다. 일반적으로 1 세 경에 인 공와우이식을 받는 심도 감각신경성난청 아동의 경우, 수술 전 유발이음향방사검사와 청성뇌간반응검사 등 객관적 청 력검사에서 반응이 나타나지 않고 보청기 착용에도 청능발 달에 진전이 없어 수술을 시행하게 된다. 술 전 MRI를 통해
내이와 내이도, 청신경의 구조적 이상 여부를 확인하지만, 소뇌교각 부위나 내이도 근위부에 위치한 8번 뇌신경의 분 지는 비교적 확인이 용이한 반면 내이도 원위부의 와우신경 은 해상도의 문제 등으로 인해 정확히 확인되지 않는 경우 가 있다. 즉, 기능하는 와우신경의 존재에 대한 객관적인 확 인이 완료되지 않은 상태에서 인공와우이식이 시행되는 경 우가 있을 수 있다. 내이도 협착이 없는 와우신경부전은 극 히 드물기 때문에 이러한 경우라도 대부분은 이식 후 양호 한 결과를 얻을 수 있으나, 만일 와우신경부전이 있는 경우 라면 이식 후 결과가 매우 부진하거나 청각 자극에 실패할 수 도 있다. 따라서 모든 인공와우이식 대상자에 있어서 행동 반응 청력검사, 전기생리학적 검사, 영상검사, 그리고 말-언 어 평가 등의 검사 결과를 종합하여 기능하는 와우신경의 존재를 확인한 후 수술 여부를 결정해야 할 것이다.

\section{REFERENCES}

1) Kim LS, Jeong SW, Lee YM. Diagnostic evaluation of difficult cases in pediatric cochlear implant. Korean J Audiol 2006;10(1):3-11.

2) Kim LS, Jeong SW, Lee YM, Kim JS. Cochlear implantation in children. Auris Nasus Larynx 2010;37(1):6-17.

3) Shelton C, Luxford WM, Tonokawa LL, Lo WW, House WF. The narrow internal auditory canal in children: a contraindication to cochlear implants. Otolaryngol Head Neck Surg 1989;100(3):227-31.

4) Gray RF, Ray J, Baguley DM, Vanat Z, Begg J, Phelps PD. Cochlear implant failure due to unexpected absence of the eighth nerve--a cautionary tale. J Laryngol Otol 1998;112(7):646-9.

5) Maxwell AP, Mason SM, O’Donoghue GM. Cochlear nerve aplasia: its importance in cochlear implantation. Am J Otol 1999;20(3):335-7.

6) Papsin BC. Cochlear implantation in children with anomalous cochleovestibular anatomy. Laryngoscope 2005;115(1 Pt 2 Suppl 106): $1-26$.

7) Kim LS, Jeong SW, Huh MJ, Park YD. Cochlear implantation in children with inner ear malformations. Ann Otol Rhinol Laryngol 2006;115(3):205-14.

8) Nelson EG, Hinojosa R. Aplasia of the cochlear nerve: a temporal bone study. Otol Neurotol 2001;22(6):790-5.

9) Casselman JW, Offeciers FE, Govaerts PJ, Kuhweide R, Geldof H, Somers T, et al. Aplasia and hypoplasia of the vestibulocochlear nerve: diagnosis with MR imaging. Radiology 1997;202(3):773-81.

10) Adunka OF, Roush PA, Teagle HF, Brown CJ, Zdanski CJ, Jewells $\mathrm{V}$, et al. Internal auditory canal morphology in children with cochlear nerve deficiency. Otol Neurotol 2006 ;27(6):793-801.

11) Casselman JW, Offeciers EF, De Foer B, Govaerts P, Kuhweide R, Somers T. CT and MR imaging of congential abnormalities of the inner ear and internal auditory canal. Eur J Radiol 2001;40(2):94104.

12) Thai-Van H, Fraysse B, Berry I, Berges C, Deguine O, Honegger A, et al. Functional magnetic resonance imaging may avoid misdiagnosis of cochleovestibular nerve aplasia in congenital deafness. Am J Otol 2000;21(5):663-70. 